\title{
Pulmonary embolism presenting as adult respiratory distress syndrome-support for a hypothesis
}

\author{
AdRian J. Williams \\ M.B., M.R.C.P. \\ David C. Yauch \\ M.D.
}

\author{
STEPHEN N. FinberG \\ D.O. \\ Silverio M. Santiago Jr \\ M.D.
}

\author{
H. KENNETH FISHER \\ M.D., F.A.C.P., F.C.C.P.

\begin{abstract}
The Pulmonary Division, Department of Medicine VA Wadsworth Medical Center, Los Angeles, and University of California at Los Angeles, California 90073, U.S.A.
\end{abstract}

\begin{abstract}
Summary
Adult respiratory distress syndrome (ARDS), or noncardiogenic pulmonary oedema, has only rarely been associated with pulmonary embolism. In this case study the association is further documented and the occurrence of pulmonary oedema confined to unobstructed portions of the pulmonary capillary bed is illustrated.

\section{Introduction}

Adult respiratory distress syndrome (ARDS), or non-cardiogenic pulmonary oedema, is known to complicate classic pulmonary embolism (Robin, Cross and Zelis, 1973). It has been well documented in animal experiments (Singer et al., 1957; Swenson, Lamas and Ring, 1965; Parmley, North and Ott, 1962) but is rare in man (Meth et al., 1975). A number of mechanisms have been proposed including the notion that major occlusions of the pulmonary vasculature may result in pulmonary hypertension with transmission of the high pulmonary arterial pressure to unobstructed portions of the pulmonary capillary bed (Robin et al., 1973). Nevertheless, this has not been demonstrated in man and the present case is presented in support of this hypothesis. The patient described here had angiographically documented pulmonary emboli and developed pulmonary oedema confined to unobstructed segments and in the presence of a normal pulmonary capillary 'wedge' pressure.
\end{abstract}

\section{Case report}

A 61-year-old man underwent radical excision of a malignant squamous cell tumour of the oropharynx. His past history was significant for myocardial infarcts sustained in 1962 and 1965, and systemic arterial hypertension under treatment with hydralazine. The pre-operative chest radiograph was normal except for moderate cardiomegaly (cardiac $\vec{z}$ diameter $16 \mathrm{~cm}$ ) (Williams, 1977). The surgical procedure included a prophylactic tracheostomy with $\vec{\oplus}$ hemimandibulectomy, hemimaxillectomy and radica $\biguplus_{\infty}$ neck dissection. His postoperative course was up remarkable for the next $72 \mathrm{hr}$ but following transfer from the intensive care unit to the ward, the patie was found to be tachypnoeic and hypotensive (blood pressure $80 / 60 \mathrm{mmHg}$ ) with a heart rate of $150 / \mathrm{min}$. ٌ Arterial blood gases breathing room air were ab- $\stackrel{\mathbb{Q}}{\complement}$ normal: pH 7.32, $\mathrm{PO}_{2} 52 \mathrm{mmHg}, P_{\mathrm{CO}_{2}} 28 \mathrm{mmHg}$. A $\overrightarrow{\vec{F}}$ chest radiograph (Fig. 1) revealed bilateral acinar 3 shadows sparing both lower zones and consistent $\bar{\partial}$ with pulmonary oedema. There was no increase in heart size. An electrocardiogram showed no change from the preoperative record apart from a sinus 3 tachycardia. A diagnosis of pulmonary oedema was made and $80 \mathrm{mg}$ of frusemide was administered intravenously, with a resulting diuresis of 2 litres $ᄋ$ over the next $2 \mathrm{hr}$. Nevertheless no improvement was apparent in the patient's clinical status, arterial 응 blood gases or chest radiograph. A flow-directed $D$ pulmonary artery catheter was inserted and the pulmonary artery pressure was found to be $25 / 5 \mathrm{~N}$ $\mathrm{mmHg}$, with a mean of $16 \mathrm{mmHg}$. The pulmonary capillary 'wedge' pressure was $3 \mathrm{mmHg}$.

Because of the confusing clinical and radio- N graphic picture a pulmonary angiogram was per- $\mathcal{O}$ formed (Fig. 2). This demonstrated intraluminalo filling defects in arteries to both lower lobes co- $\mathbb{\mathbb { D }}$ incident with the non-oedematous areas (Fig. 3). A $\stackrel{\oplus}{+}$ diagnosis of pulmonary embolism was thus con- 7 firmed and anticoagulant therapy with intravenous $\stackrel{\vec{D}}{\mathbb{D}}$

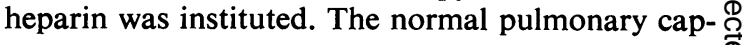




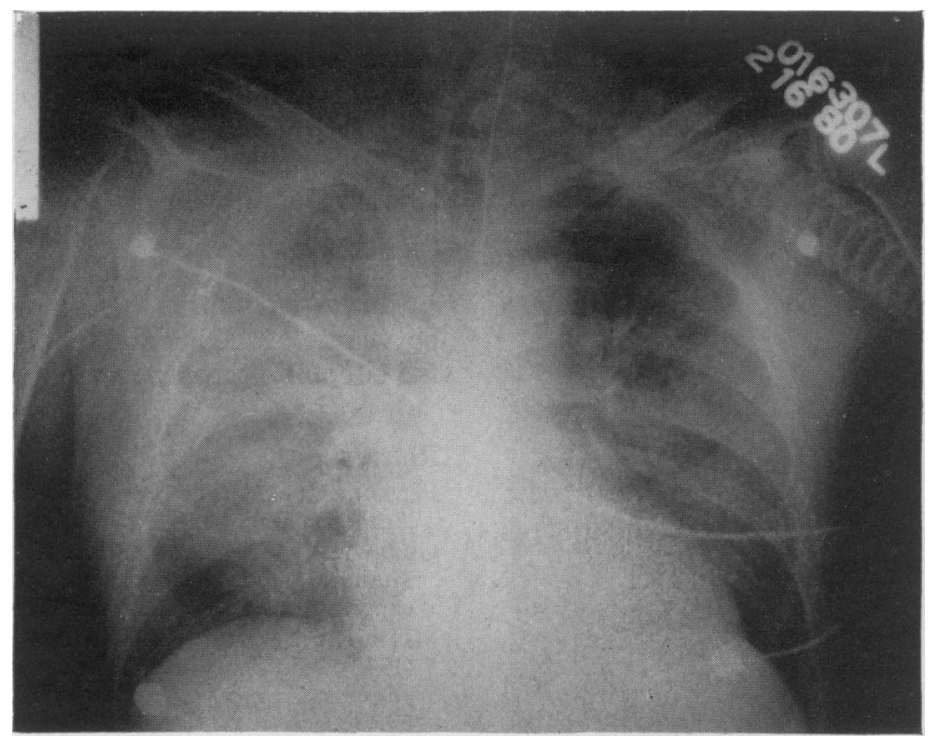

FIG. 1. Anterioposterior chest radiograph showing bilateral diffuse homogeneous opacities consistent with an alveolar filling process such as pulmonary oedema. Both lower zones are noticeably spared.

illary 'wedge' pressure excluded left ventricular failure, and the radiographic abnormality was interpreted as non-cardiogenic pulmonary oedema. The patient was subsequently managed by fluid restriction and artificial ventilation. A fractional inspired

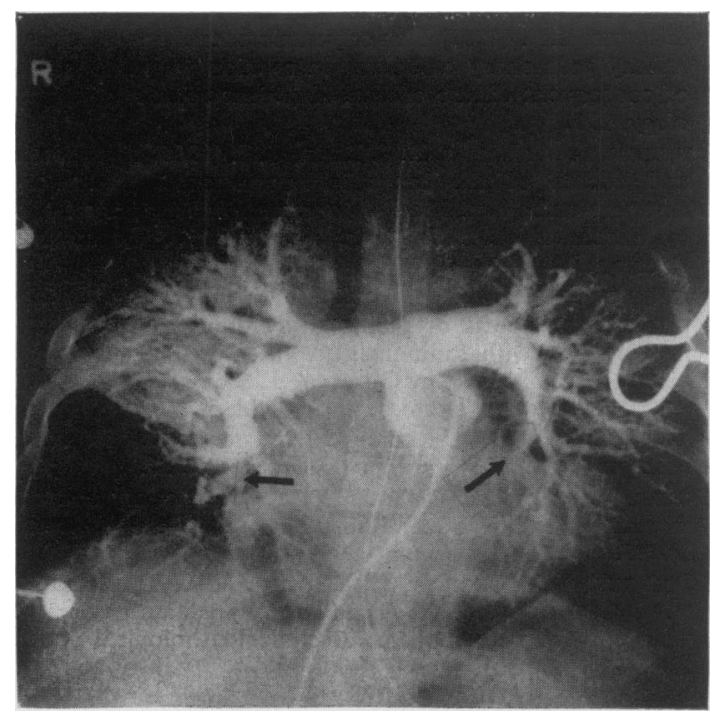

FIG. 2. Pulmonary angiogram showing absent filling of vessels in both lower zones particularly on the right. Intraluminal filling defects $(\rightarrow)$ were identified in branches of the right and left basal arteries.
$\mathrm{O}_{2}$ concentration $\left(\mathrm{F}_{1} \mathrm{O}_{2}\right)$ of 1.0 was initially required to maintain an arterial $\mathrm{Po}_{2}$ of $50 \mathrm{mmHg}$, so that positive end expiratory pressure (PEEP) of $15 \mathrm{~cm}$ $\mathrm{H}_{2} \mathrm{O}$ was gradually introduced. Over the next $48 \mathrm{hr}$ oxygenation improved (together with the radiographic appearance), and the $\mathrm{F}_{1} \mathrm{O}_{2}$ was reduced to 0.4 and the level of PEEP to $10 \mathrm{~cm} \mathrm{H}_{2} \mathrm{O}$. On this regime arterial blood gases were: $P_{2} 59 \mathrm{mmHg}$; $\mathrm{PCO}_{2} 35 \mathrm{mmHg} ; \mathrm{pH} \mathrm{7 \cdot 44}$. Five days after respiratory failure had first developed broad-spectrum antibiotic coverage was begun for fever of uncertain source. One day later the patient suffered a cardiac arrest and could not be resuscitated. Permission for a postmortem examination was denied.

\section{Discussion}

Pulmonary oedema is recognized as a complication of pulmonary embolism (Short, 1952; Felson, 1973) but usually occurs in those patients with left ventricular dysfunction (Yuceoglu et al., 1971) and in these individuals is thought to be due to left ventricular failure. Non-cardiogenic pulmonary oedema, or ARDS, occurs in a wide variety of clinical settings such as hypovolaemic shock, major trauma and septicaemia. It has been described as a complication of classic pulmonary thromboembolism by Windebank and Moran (1973), and in more detail in a case report by Meth et al. (1975), though in this instance no pulmonary capillary 'wedge' pressures were obtained. In the present case pulmonary embolism was documented by angiography and the normal capillary 'wedge' pressures exclude left ventricular 
failure as a cause of the pulmonary oedema. Although it might be argued that therapy with frusemide early in the course of the respiratory failure had 'cured' any left ventricular failure that was present, it is noteworthy that the patient's clinical state did not improve. At no time was the 'wedge' pressure greater than $10 \mathrm{~cm} \mathrm{H}_{2} \mathrm{O}$ and it therefore seems clear that this was truly a case of non-cardiogenic pulmonary oedema or ARDS.

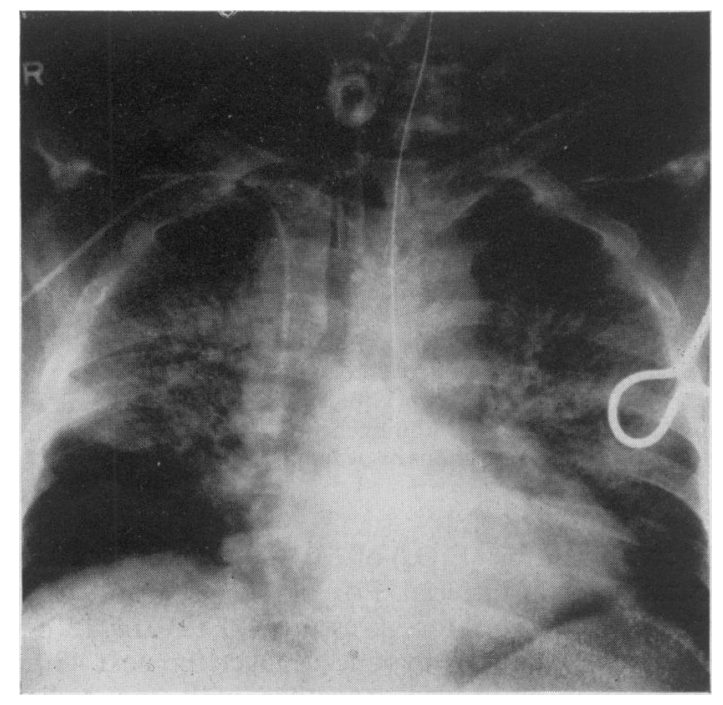

FIG. 3. Anterioposterior chest radiograph taken immediately before catheterization of the pulmonary artery to show the limited distribution of the radiodensity.

The case is interesting not only because this ARDS was associated with pulmonary embolism but also because the alveolar oedema was initially confined to areas not obstructed by clot. This has implications for any theory of pathogenesis. It has been proposed that the release of vasoactive substances from clots may lead directly to increased capillary permeability (Gurewich, Cohen and Thomas, 1968), or to venoconstriction and an increased capillary hydrostatic pressure (Swenson, quoted by Robin, 1970); in addition, it is possible that fibrin microemboli may injure pulmonary capillaries (Saldeen 1976). All these possibilities would, of course, be expected to produce oedema 'downstream' of the obstruction. Another mechanism may be maldistribution of blood flow causing some areas of lung to be overperfused. In this instance, the unobstructed areas of the pulmonary circulation would be subjected to high regional pressures resulting in intersti- $\frac{3}{3}$ tial and alveolar oedema (Ohkuda et al., 1978). $\stackrel{\mathbb{\Phi}}{\stackrel{2}{\perp}}$ Because the obstructed areas were unaffected by $c$. oedema in the present case, this hypothesis seems $\overrightarrow{\vec{F}}$ tenable. The absence of overall pulmonary hyper- $\stackrel{\text { ? }}{+}$ tension does not exclude the possibility since local $\frac{\mathrm{C}}{\mathrm{C}}$ pressures may have been transiently quite high.

This case confirms that pulmonary embolism may $\frac{\bar{m}}{7}$ be a cause of ARDS and that obstructed portions of $\mathscr{\complement}$ the circulation may be spared.

\section{References}

Felson, B. (1973) The bronchiolo-alveolar system. In: Chest Roentgenology, p. 295. W.B. Saunders, Philadelphia.

Gurewich, V., Cohen, M.L. \& Thomas, D.P. (1968). Humoral factors in massive pulmonary embolism: An 3 . experimental study. American Heart Journal, 76, 784. is

Meth, R.F., TAshin, D.P., Hansen, K.S. \& Simmons, D.H. (1975) Pulmonary edema and wheezing after pulmonary embolism. American Review of Respiratory Diseases, 111,

Ohkuda, K., Nakahara, K., Weidner, W.P., Binder, A. \& StaUb, N.C. (1978) Lung fluid exchange after uneven 윽 pulmonary artery obstruction in sheep. Circulation Research, 43, 152.

Parmley, L.F., North, R.L. \& OTt, B.S. (1962) Hemodyn- 이 amic alterations of acute pulmonary embolism. Circulation $<$ Research, 11, 450.

Robin, E.D., Cross, E.C. \& Zelis, R. (1973) Pulmona\& 용 edema. New England Journal of Medicine, 1973, 288.

SALdeEn, T. (1976) The microembolism syndrome. Micrō: vascular Research, 11, 227.

SHORT, D.S. (1952) A survey of pulmonary embolism in a $\frac{\partial}{0}$ general hospital. British Medical Journal, 1, 790.

Singer, D., Saltman, P.W., Rivera-Estrada, C., Pick, R. 요 \& KATZ, L.N. (1957) Hemodynamic alterations following miliary pulmonary embolism in relation to pathogenesis $\overrightarrow{\overrightarrow{0}}$ of consequent diffuse edema. American Journal of Physi- $\frac{0}{3}$ ology, 191.

SWEnson, B.W., LAMAS, R. \& Ring, G.C. (1965) Hypoxemia and edema of the lungs in experimental pulmonary thrombo-embolism. In: Pulmonary Embolic Disease. (Ed $\bar{\partial}$ by Sasahara, A.A. \& Stein, M.), p. 170. Grune and 3 Stratton, New York.

SwENson, D.W. [Quoted by Robin, E.D.] (1970). Patho- 3 . physiologic aspects of pulmonary embolism, pulmonary investigation with radionuclides. In: First annual nuclear medicine seminar. (Ed by Gilson, A.J. \& Smoak III, W.M.), p. 340. Charles C. Thomas, Springfield. 340.

Williams, A.J. (1977). Radiographic assessment of cardiac enlargement. American Heart Journal 93, 536.

Windebank, W.J. \& Moran, F. (1973) Pulmonary oedema in pulmonary thromboembolism. British Medical Journal, N $1,485$.

Yuceoglu, Y.Z., Rubler, S., EshWAR, K.P., TChertKoff, N V. \& GRISHMAN, A. (1971) Pulmonary edema associated N with pulmonary embolism: A clinicalpathological study. Angiology, 22, 501. 